\title{
La Secretaría General Técnica: un órgano con un horizonte muy prometedor para la reforma administrativa
}

\author{
Moisés Barrio Andrés \\ Letrado del Consejo de Estado \\ moises.barrio@consejo-estado.es
}

SUMARIO

I. INTRODUCCIÓN. II. ORÍGENES Y EVOLUCIÓN. III. FUNCIÓN CONSULTIVA DE LAS SECRETARÍAS
GENERALES TÉCNICAS. IV. CONFIGURACIÓN ACTUAL. V. PROYECCIÓN FUTURA. VI. BIBLIOGRAFÍA.

\section{INTRODUCCIÓN}

La Secretaría General Técnica es uno de los órganos centrales característicos de la Administración General del Estado, presente en todos los Ministerios, que desempeña funciones de asistencia técnica y administrativa al titular y a los órganos superiores del Departamento, de tramitación de los expedientes elevados al Consejo de Ministros y de coordinación institucional, tanto a nivel interno, manteniendo las oportunas relaciones con los distintos centros directivos del Departamento, como externo, actuando como cauce de comunicación con el resto de los Ministerios y Administraciones públicas.

Su nacimiento fue disperso en el tiempo y originariamente eran verdaderos cajones de sastre a los que iban a parar las competencias residuales no ejercidas por otros servicios o Direcciones Generales del Departamento, tal y como recuerda CARRO MARTÍNEZ1'. Después, tras su generalización con la Ley de Régimen Jurídico de la Administración del Estado, de 26 de julio de 1957 (LRJAE en lo sucesivo) las Secretarías Generales Técnicas se configuran como órganos auxiliares y de asesoramiento, consagrando en nuestra estructura organizativa el sistema y técnica del staff and line.

En la actualidad, tras haber superado ciertos embates que pretendían su desaparición, la Secretaría General Técnica es un órgano definitivamente asentado en la estructura departamental española de los Ministerios, Consejerías autonómicas y en el Ayuntamiento de Madrid. No obstante, este órgano todavía ofrece posibilidades para potenciar su papel y funciones para coadyuvar en la mejora del funcionamiento de nuestra Administración.

Con carácter limitar, debe examinarse su origen y desarrollo.

\section{ORÍGENES Y EVOLUCIÓN}

El nacimiento de las Secretarías Generales Técnicas no deriva de un mismo impulso fundacional. Por el contrario, su origen varía según los distintos Ministerios, que fueron incorporando a su estructura orgánica una unidad con esa denominación de forma un tanto dispersa en el tiempo, aunque respondiendo a unas necesidades y con unos objetivos y fines similares.

La primera vez que en nuestro Ordenamiento jurídico aparece la expresión «Secretaría General Técnica» es en la Ley de 16 de julio de 1938, por la que se crean las Comisiones Reguladoras de la Producción, que contempla, en su art. 8, una referencia a las Secretarías Técnicas Generales, organizadas en cada uno de los Ministerios de Industria y Comercio y de Agricultura, bajo la directa dependencia del Ministro, como órgano asesor del mismo en todo lo que se refiere a organización y funcionamiento de esas Comisiones, tramitando sus informes y propuestas. Asimismo, son el órgano a través del que se establecen la dependencia de las Comisiones reguladoras y su coordinación con los respectivos Departamentos.

1 CARRO MARTÍNEZ, Antonio: “Secretarías Generales Técnicas”, en AA.VV.: Estudios de Derecho Administrativo. Libro Jubilar del Consejo de Estado. Editorial Instituto de Estudios Políticos, Madrid, 1972, pág. 268. 
Sobre esa base, el Ministerio de Agricultura organiza, mediante Orden de 2 de diciembre de 1939, la Secretaría Técnica General del Ministerio de Agricultura como el "organismo que en cumplimiento de lo ordenado en el art. 8 de la Ley de 16 de julio de 1938 ha de establecer, bajo la dependencia directa del Ministro, la coordinación de las actividades de las distintas Comisiones Reguladoras, de la Producción en cuanto se refiere a las funciones y problemas que afectan a este Ministerio". Aparte de órgano asesor del Ministro en todo lo relativo a la organización y funcionamiento de las Comisiones Reguladoras de la Producción, le incumbe informar al Ministro sobre los presupuestos y estados de cuentas, previamente analizados en dichas Comisiones Reguladoras, y asume también las funciones que anteriormente tenía encomendadas la Asesoría Técnica. Asimismo, esa Orden dispone que el titular de la Secretaría Técnica General es designado por el Ministro, y puede, por delegación de éste, relacionarse con el Secretario Técnico General del Ministerio de Industria y Comercio, así como con las Direcciones Generales de ambos Ministerios.

La denominación actual (que supone solamente la alteración en el orden de los términos) se produce en 1952 mediante un Decreto de 8 de febrero, por el que se organiza la Secretaría General Técnica, con la categoría administrativa de Dirección General, bajo la dependencia inmediata del Ministro, correspondiéndole las funciones de información y asesoramiento en la esfera económica, así como de ordenación, regulación y distribución de las producciones agrícolas atribuidas al Ministerio de Agricultura.

Por su parte, el mencionado Ministerio de Industria y Comercio también experimenta en 1939 una reorganización, aprobada mediante una Ley de 9 de noviembre, que, además de afectar a otras unidades, establece la creación de una Secretaría General Técnica, con categoría administrativa de Dirección General, cuyo titular será designado libremente en Consejo de Ministros, a propuesta del de Industria y Comercio, dependiendo inmediatamente de él. Su creación tiene como finalidad "lograr una mayor eficiencia en la labor a realizar", y se impone "con el objeto de atender a necesidades que la experiencia de casi dos años de funcionamiento ha puesto de manifiesto".

Tras una reorganización de la planta ministerial, posteriormente es erigido por partenogénesis el Ministerio de Comercio, con la consiguiente creación de la correspondiente Secretaría General Técnica mediante Decreto-Ley de 27 de julio de 1951. En cuanto a su categoría y la designación de su titular ello no difiere de los casos anteriores. El art. 2 establece que le corresponden las funciones que en el orden económico-comercial de información, regulación y distribución son propias del Ministerio de Comercio, si bien el art. 3 dice que la organización y funciones de la Secretaría General Técnica "serán establecidas a través de las oportunas disposiciones...". La disposición sería una Orden de 1 de septiembre de 1951, entre cuyas funciones contempla las de "estudio, asesoramiento y coordinación en las materias propias de la competencia del Departamento; proponer y ejecutar las resoluciones convenientes en los problemas comerciales no atribuidos a otros Organismos del Ministerio, y mantener la conexión y enlace, en materia de economía, con las demás ramas de la Administración y con los Organismos y Entidades de carácter económico". Para el desempeño de esas funciones, se estructura en los siguientes servicios: Asuntos generales; Estudios, investigación y publicaciones económicas; Productos, precios y mercados; y Distribución, transporte y consumo.

En esta etapa embrionaria también debemos hacer referencia al Ministerio de Educación Nacional, donde la Secretaría General Técnica nace de la reorganización ${ }^{2}$ de los Gabinetes Técnicos del Departamento, de forma que el Gabinete Técnico de la Secretaría del Departamento se estructura como Secretaría General Técnica, dependiente directamente del Ministro. De ella forman parte, junto a su titular, los Secretarios-Jefes de todos los Gabinetes Técnicos del Ministerio que, aunque continúen desarrollando sus funciones bajo la dirección inmediata del Subsecretario y de los Directores Generales respectivos en los asuntos específicos de su competencia, se coordinarán entre sí, a través de la Secretaría General Técnica, el Jefe del Servicio de Publicaciones, los oficiales técnicos adscritos al Ministerio y los asesores auxiliares que el Ministro considere conveniente. Su misión principal es la recopilación de informes y documentos sobre problemas culturales de España y del extranjero; la revisión, reajuste y publicación de las disposiciones legales y complementarias correspondientes a la órbita de actividad de este Departamento y la preparación de los proyectos de nuevas normas jurídicas que se le encomienden.

Por último, debemos aludir a la Presidencia del Gobierno. Por Decreto-Ley de 20 de diciembre de 1956 se crea la Secretaría General Técnica en la Presidencia del Gobierno. Como en los supuestos anteriores, funciona a las órdenes inmediatas del Ministro Subsecretario, como órgano de estudio y documentación, asistencia técnica, coor-

2 La norma que configura la Secretaría General Técnica del Ministerio de Educación Nacional como un organismo con entidad propia, dotándola de la jerarquía y los medios correspondientes, es una Ley de 14 de abril de 1955, que lleva a cabo una reorganización importante del Departamento. Como justificación, en el preámbulo de dicha Ley se hace referencia a la necesidad creciente de estudios técnicos y de planeamiento que habían dado origen a los Gabinetes técnicos y cómo éstos se habían integrado organizando la Secretaría General Técnica. Asimismo, se resalta la importantísima función que desempeña, "de acuerdo con la experiencia ya realizada satisfactoriamente en otros Departamentos”. La Ley contempla la Secretaría General Técnica como órgano de estudio y documentación, asistencia técnica y elaboración de planes del Departamento, que funciona a las órdenes inmediatas del Ministro, sin perjuicio de las demás funciones de delegación que específicamente se le atribuyen. 
dinación y elaboración de planes de la Presidencia del Gobierno, especialmente en cuanto se refiera a la reforma y perfeccionamiento de la organización y actividad administrativas.

Dicho momento constituye un hito fundamental para la configuración de las Secretarías Generales Técnicas en España. Hasta la fecha, habían apuntado aspectos novedosos pero sin aparecer todavía con un perfil bien definido. En cambio, después las Secretarías Generales Técnicas se configuran nítidamente como órganos staff, orientados fundamentalmente hacia la reforma administrativa. Recuérdese que el profesor LÓPEZ RODÓ fue el primer Secretario General Técnico de la Presidencia del Gobierno.

En efecto, hasta 1956 las pocas Secretarías Generales Técnicas aparecieron como un órgano de perfil borroso, como primer paso hacia la incorporación en nuestra Administración del sistema staff and line, ya que cada vez se hacía notar más la necesidad de unidades institucionalizadas para la prestación de asesoramiento y asistencia técnica constantes. Será la LRJAE de 1957 la que opere la generalización de la existencia de Secretarías Generales Técnicas en los Ministerios y, por ende, la consagración en nuestra estructura organizativa del sistema y técnica del staff and line. Precisamente, el Maestro GARCÍA DE ENTERRÍA ${ }^{3}$ calificó a este hecho como la más importante de las innovaciones introducidas por la Ley de Régimen Jurídico de 1957.

Aunque no se impone como unidad que deba existir de forma obligatoria en todos los Ministerios, la LRJAE prevé que se establezca en los Ministerios que carecen de ella, asignándole las funciones de "estudio y documentación en las materias propias del Departamento, así como la formulación de planes generales de actuación del Ministerio y la coordinación de los planes particulares de los distintos Centros Directivos". Más concretamente, el perfil de la Secretaría General Técnica a partir de ese momento está recogido en el art. 19 de la LRJAE:

“En los Ministerios Civiles podrá existir un Secretario general técnico, con categoría de Director general, para realizar estudios y reunir documentación sobre las materias propias del Departamento, especialmente en orden a:

1. Elaborar los proyectos de planes generales de actuación y los programas de necesidades del Departamento.

2. Prestar asistencia técnica y administrativa al Ministro en cuantos asuntos éste juzgue conveniente, con vistas a la coordinación de los servicios.

3. Proponer las reformas que se encaminen a mejorar y perfeccionar los servicios de los distintos centros del Ministerio y preparar la relativa a su organización y métodos de trabajo, atendiendo, principalmente, a los costes y rendimientos.

4. Proponer las normas generales sobre adquisición de material y cuantas disposiciones afecten al funcionamiento de los servicios.

5. Preparar compilaciones de las disposiciones vigentes que afecten al Ministerio, proponer las refundiciones o revisiones de textos legales que se consideren oportunos, y cuidar de las publicaciones técnicas, periódicas o no, del Ministerio.

6. Dirigir y facilitar la formación de las estadísticas acerca de las materias de la competencia del Departamento, en colaboración con el Instituto Nacional de Estadística, y las demás que se estimen convenientes.

Para el cumplimiento de las anteriores funciones podrá recabar de las Direcciones Generales y Organismos del Departamento, así como de sus Servicios descentralizados, cuantos informes, datos y documentos considere precisos para el cumplimiento de sus fines."

En todo caso, la LRJAE matizó con suficiente precisión la naturaleza staff de las Secretarías Generales Técnicas, al no atribuirles facultades ejecutivas ni decisorias. Obsérvese, sin embargo, que el precepto rehúye toda alu-

3 GARCÍA DE ENTERRÍA Y MARTÍNEZ CARANDE, Eduardo: La Administración española: estudios de ciencia administrativa. Editorial Cívitas, Madrid, 1999, pág. 92. 
sión a facultades consultivas o asesoras, a pesar de que la redacción del proyecto inicial sí aludía expresamente a la función de informe. Cuenta CARRO MARTíNEZ ${ }^{4}$ que ello fue debido al temor de los órganos consultivos clásicos que venían con prevención competencial esta eclosión radiante de las Secretarías Generales Técnicas.

No obstante, su papel se vio fortalecido un año más tarde al atribuirles cierta función consultiva con la aprobación de otra de las leyes que han marcado la vida administrativa de las últimas décadas, la Ley de Procedimiento Administrativo. Esta ley, que nace con el objetivo de reunir las normas de procedimiento dispersas en un texto único aplicable a todos los Departamentos ministeriales (con alguna salvedad), al tratar el procedimiento para la elaboración de disposiciones de carácter general establece que éstas, antes de su aprobación por el órgano competente, deben ser informadas por la Secretaría General Técnica (o, en su defecto, la Subsecretaría) del Departamento respectivo, dando origen al conocido «Informe 130.1».

Ahora bien, debe reconocerse que las Secretarías Generales Técnicas nunca tuvieron intenciones desviacionistas respecto de las competencias de los tradicionales órganos consultivos del Estado. El asesoramiento del órgano staff, incardinado lateralmente en la organización jerárquica, es perfectamente compatible con el asesoramiento del órgano colegiado y externo a la organización jerárquica. Por ello, en la actualidad no existen dudas ni reservas ${ }^{5}$ respecto a la función consultiva de las Secretarías Generales Técnicas.

La positiva experiencia de los Ministerios donde ya existía y el impulso que supuso esta normativa llevó a la generalización ${ }^{6}$ de la Secretaría General Técnica en todos los Departamentos. Así, el Decreto de 27 de noviembre de 1967, de reorganización de la Administración Civil para reducir el gasto, se refiere ya a la Secretaría General Técnica como "uno de los servicios generales que existe en todos los Departamentos" junto a la Subsecretaría. Este Decreto, a su vez, refuerza ese proceso, pues con él la Secretaría General Técnica, sin perjuicio de cualquier otra función que le corresponda, se convierte en un órgano que "integrará en sus servicios las funciones que puedan existir dispersas en los restantes organismos", cargando el acento sobre las funciones auxiliares y especialmente las referidas a estadística, bibliotecas, documentación y archivo general, publicaciones, información al público, relaciones públicas, iniciativas, reclamaciones y derecho de petición.

Sin embargo, como ha advertido SANTAMARÍA PASTOR7, su puesta en práctica resultó bastante irregular y llena de dificultades, pues el nuevo órgano terminó entrando en conflicto con los restantes del Ministerio: de un lado, con la Subsecretaría, en cuyo ámbito funcional venía a incidir el nuevo órgano (dado que la LRJAE atribuye competencias en materia de elaboración de programas de necesidades del Departamento y de normas sobre adquisición de material, art. 19.1 y 4 LRJAE); de otro lado, con las Direcciones Generales, sobre las que un órgano de igual rango incide en su esfera competencial elaborando los planes generales de actuación del Ministerio y proponiendo las reformas en su organización y métodos de trabajo, y en los textos legales por los que se rige su actividad (art. 19.1, 3 y 5 LRJAE).

El resultado de estas tensiones fue situar la Secretaría General Técnica bajo la dependencia de la Subsecretaría, al tiempo que las Direcciones Generales tendieron a duplicar los servicios de aquella en lo que se refiere a los servicios de asistencia y documentación. De esta forma, diversas Secretarías Generales Técnicas se vieron paulatinamente desplazadas a realizar actividades de asistencia meramente residuales, lo cual asimismo fue menoscabada con la potenciación de los Gabinetes políticos de los Ministros y de los Secretarios de Estado, llegándose a cuestionar incluso su permanencia.

Finalmente, la Ley 6/1997, de 14 de abril, de Organización y Funcionamiento de la Administración General del Estado (LOFAGE en lo sucesivo) ha mantenido esta figura, señalando que "los Secretarios generales técnicos, bajo la inmediata dependencia del Subsecretario, tendrán las competencias sobre servicios comunes que les atribuyan el Real Decreto de estructura del Departamento y, en todo caso, las relativas a: producción normativa, asistencia jurídica y publicaciones" (art. 17.1 LOFAGE), y que en idénticos términos reproduce el art. 65.1 del Proyecto de Ley de Régimen Jurídico del Sector Público (PLRJSP en lo sucesivo).

4 Op. cit., pág. 280 . Señala asimismo que la función de evacuar informes técnicos del proyecto no prosperó en las Cortes como consecuencia de haberse aceptado una enmienda suscrita por García Hernández -Abogado del Estado- y otros Procuradores, en la que se afirmaba que algunas Secretarías Generales Técnicas seguían una viciosa trayectoria, puesto "que tienden a convertirse en órganos de asesoramiento jurídico, con merma de las facultades reconocidas a otros de indudable abolengo en la Administración pública española, tales como la Dirección General de lo Contencioso del Estado y el Consejo de Estado".

5 FONT I LLOVET, Tomás: “Órganos consultivos”, en Revista de Administración Pública, núm. 108, 1985.

6 La generalización, con todo, no es inmediata. Así en el Ministerio de Gobernación la creación se produce por Decreto de 21 de septiembre de 1960 (BOE de 11 de octubre). En el Ministerio de Justicia la Secretaría General Técnica se crea mediante Decreto de 12 de marzo de 1964.

7 SANTAMARIA PASTOR, Juan Alfonso: Fundamentos de Derecho Administrativo. Editorial CEURA, Madrid, 1988, pág. 1002. 
Antes de analizar su configuración actual en nuestro derecho positivo debemos realizar un breve apunte sobre su función consultiva.

\section{FUNCIÓN CONSULTIVA DE LAS SECRETARÍAS GENERALES TÉCNICAS}

La doctrina ${ }^{8}$, al analizar la función consultiva, ha distinguido entre los órganos consultivos tradicionales, modelo que está representado en el máximo nivel por el Consejo de Estado, y los órganos de asesoramiento contemporáneos, modelo staff, siendo su paradigma las Secretarías Generales Técnicas, y al cual también pertenecen los Gabinetes de los Ministros y de los Secretarios de Estado y otros órganos semejantes de asesoramiento inmediato.

La función consultiva clásica responde al modelo organizativo implantado por Napoleón a finales del siglo XVIII. Este sistema sirvió para generalizar la técnica comisarial, consistente en trasladar las funciones decisorias de los Consejos a oficiales y cargos unipersonales, de estricta confianza del Rey y directamente dependientes de su persona. Desde entonces, los Consejos ejercerán únicamente funciones consultivas, consagrándose así uno de los principios básicos de la Administración Napoleónica «Déliberer est le fait des plusiers, Administrer le fait d'un seul». La función consultiva clásica se va a caracterizar, desde un punto de vista estructural, por su independencia respecto de la Administración activa, y desde una perspectiva funcional, porque su actuación es a instancia de la Administración consultante, se manifiesta de forma intermitente y mediante la fórmula solemne y formal del dictamen.

En cambio, la Administración consultiva contemporánea se desarrolló en el pasado siglo y se ha generalizado en el actual. El modelo de «Estado Mayor» norteamericano gira en torno a órganos de apoyo inmediato y se caracteriza también desde una perspectiva funcional y estructural. Desde este último punto de vista, los asesores son personas de confianza de los representantes de la Administración activa, de hecho, suelen ser nombrados y cesados con quienes les han dado su confianza política. Desde una perspectiva funcional, su intervención y asesoramiento se produce de forma permanente e informal, bien a través de informes, bien en una simple conversación, y alcanza a todas las vertientes de la actividad político-administrativa de los altos órganos de mando.

De este modo, como es sabido la diferencia capital entre los órganos consultivos tradicionales y los nuevos órganos tipo staff radica sobre todo en el método y el procedimiento de trabajo. El Consejo de Estado y otros órganos inspirados en este mismo modelo no asesoran de modo continuo, sino que responden a las consultas que les dirigen los órganos facultados para ello. Los dictámenes se elaboran, además, en el marco de un procedimiento formalizado y ritual que impone el cumplimiento de determinados trámites, la deliberación interna y la aprobación final siguiendo las reglas de formación de la voluntad del órgano colegiado. En cambio, los nuevos órganos de apoyo y asesoramiento prestan asistencia continua y sobre cualquier materia a los órganos activos, no han de atenerse a ningún procedimiento específico para emitir sus opiniones, y es característico de ellos la continuidad y la celeridad en la aportación de criterios que sirven para la adopción de las decisiones ejecutivas, al tiempo que la inmediatez y proximidad del órgano de staff puede hacer llegar matices e impresiones que nunca puede reflejar la fórmula ritual e impersonal del dictamen.

Por ello, cabe afirmar que en la fórmula de las Secretarías Generales Técnicas se recogen las modernas corrientes orientadoras de una nueva configuración de la Administración, pero dentro del marco de una organización administrativa consolidada.

Expuesto lo anterior, nos corresponde ahora exponer su configuración actual en el derecho positivo español.

\section{CONFIGURACIÓN ACTUAL}

La regulación de las Secretarías Generales Técnicas viene establecida, como ya se ha señalado, en el art. 17 de la LOFAGE, que miméticamente viene a reproducir el art. 65 del PLRJSP, con la salvedad de actualizar la referencia del nombramiento de su titular a los cambios acaecidos en materia de función pública9.

Los rasgos legales del estatuto personal de los Secretarios Generales Técnicos son muy similares a los de los Directores Generales: del mismo rango formal que éstos, tienen también la consideración de personal de confianza política, de altos cargos y órganos directivos de los Ministerios. Son, por consiguiente, nombrados y separados libremente por el Consejo de Ministros a propuesta del Ministro respectivo, si bien el nombramiento ha de recaer

8 Vid. los estudios ya clásicos de CORSO, Pompeo: La funzione consultiva. Editorial CEDAM, Padua, 1942, y GASPARRI, Pietro: L'amministrazione consultiva. Editorial Nistri Lischi, Pisa, 1942. Entre nosotros, el revolucionario trabajo del Maestro GARCÍA DE ENTERRÍA “Estructura orgánica y administración consultiva”, incluido en su libro La Administración española, op. cit., pág. 63 y ss.

9 Éste, señala el apartado 3 del art. 65 PLRJSP, habrá de efectuarse entre funcionarios de carrera del Estado, de las Comunidades Autónomas o de las Entidades locales, pertenecientes al Subgrupo A1, a que se refiere el art. 76 de la Ley 7/2007 de 12 de abril. En todo caso, habrán de reunir los requisitos de idoneidad establecidos en la Ley 3/2015, de 30 de marzo, reguladora del ejercicio de alto cargo de la Administración General del Estado. 
en funcionarios de carrera del Estado, de las Comunidades Autónomas o de las Entidades Locales, a los que se exija para su ingreso el título de Doctor, Licenciado, Ingeniero, Arquitecto o equivalente (art. 17.3 LOFAGE y 65.3 PLRJSP).

En lo que respecta a sus funciones, la evolución experimentada por las Secretarías Generales Técnicas, de la cual se ha dado cuenta anteriormente, es la razón fundamental que impide que la descripción de sus funciones pueda ser efectuada exclusivamente con base en los datos legales, que son bastante inexpresivos. Las Secretarías Generales Técnicas, dice lacónicamente el art. 17.1 de la LOFAGE, "bajo la inmediata dependencia del Subsecretario, tendrán las competencias sobre servicios comunes que les atribuya el Real Decreto de estructura del Departamento y, en todo caso, las relativas a producción normativa, asistencia jurídica y publicaciones".

Pero esta descripción resulta enteramente insuficiente. En la práctica, los Secretarios Generales Técnicos desempeñan otras múltiples funciones de asistencia jurídica y técnica al Subsecretario y al Ministro en ámbitos sumamente variados que aparecen precisados en el correspondiente Real Decreto que establece la estructura orgánica de cada Ministerio. En ellos se contemplan funciones relativas a los asuntos sometidos a estudio y aprobación por los órganos colegiados del Gobierno (Consejo de Ministros, Comisiones Delegadas del Gobierno y Comisión General de Secretarios de Estado y Subsecretarios), ya sea de tramitación, estudio e informe o únicamente de informe.

Las funciones que, de acuerdo con el meritado art. 17 de la LOFAGE, conforman el tronco común formado por la producción normativa, la asistencia jurídica y publicaciones quedan recogidas en las normas de estructura departamental con diversas denominaciones: elaboración y tramitación de disposiciones de carácter general, compilación legislativa; estudios e informes (ya sea de los proyectos de disposición que emanan del Ministerio respectivo como remitidos por otros Ministerios e, incluso, de iniciativas parlamentarias); asistencia técnica y administrativa (a los órganos superiores y directivos del Departamento); elaboración y gestión del programa editorial del Departamento; publicación de disposiciones y actos administrativos; edición y distribución de publicaciones oficiales, etc. Por su parte, el desempeño de funciones relativas a las publicaciones generalmente se contemplan vinculadas con el desempeño de funciones de organización y dirección de biblioteca, archivo y documentación y, con frecuencia, las mismas unidades que tienen atribuidas esas funciones asumen la dirección y coordinación de la actividad estadística del Departamento.

Igualmente, aparecen atribuidas a las Secretarías Generales Técnicas de forma mayoritaria funciones relacionadas con la cooperación internacional y la acción en el exterior, la coordinación institucional dentro del Departamento, la relación con otros Departamentos y con las restantes Administraciones, así como la tramitación de los recursos administrativos y de las reclamaciones de responsabilidad patrimonial; la información administrativa y la atención al ciudadano. También es frecuente, aunque en menor medida, el desempeño de funciones en materia de organización, procedimientos y métodos de trabajo, así como la gestión de recursos y aplicaciones informáticas.

Por otro lado y de acuerdo con la descripción de funciones que, según el art. 20 de la LOFAGE, corresponde a los Servicios Comunes, y teniendo en cuenta la desaparición de la Dirección General de Servicios, algunas Secretarías Generales Técnicas asumen funciones que venían siendo propias de aquéllas. Tal es el caso de las funciones en materia de personal y relaciones sindicales; la formación y acción social; obras, y patrimonio, coordinación de Cajas Pagadoras, funciones éstas que han venido siendo desempeñadas por la Secretaría General Técnica en los Ministerios de Hacienda, Administraciones Públicas y Sanidad.

Por último, cabría hacer una referencia a un conjunto de otras funciones y servicios de contenido muy específico incluido entre las competencias de determinados Ministerios. Así, a la Secretaría General Técnica del Ministerio del Interior le corresponde la gestión del Registro Nacional de Asociaciones; a la Secretaría General Técnica del Ministerio de Educación, Cultura y Deporte el registro de los convenios que suscriba el departamento con otras Administraciones Públicas, empresas y organismos, tanto públicos como privados o el Protectorado de las fundaciones de competencia estatal que estén en el ámbito de competencias del Ministerio; o, en fin, a la Secretaría General Técnica del Ministerio de Justicia el seguimiento de las disposiciones y actos de las Comunidades autónomas, las relaciones con los juzgados y tribunales de Justicia (sin perjuicio de lo previsto por la normativa vigente en materia de representación y defensa en juicio del Estado y otras instituciones públicas) o la elaboración de los proyectos legislativos en materia penal, civil, mercantil y procesal, así como la elaboración de los proyectos de reforma del derecho nacional derivados de la transposición de directivas comunitarias o del cumplimiento de tratados o convenios internacionales celebrados por España. 


\section{PROYECCIÓN FUTURA}

De cuanto queda expuesto, las Secretarías Generales Técnicas pueden ser teorizadas desde el modelo staff and line. Quizá, como indica CARRO MARTíNEZ ${ }^{10}$, no dentro de un prototipo muy definido (al menos según la doctrina anglosajona); pero es que sus peculiaridades resultaron necesarias para adecuar con cierto éxito el sistema a la realidad de nuestra Administración. Por ello, cabe afirmar que en la fórmula de las Secretarías Generales Técnicas se recogen las modernas corrientes orientadoras de una nueva configuración de la Administración, pero dentro del marco de una organización administrativa consolidada.

Las Secretarías Generales Técnicas son hoy órganos administrativos cuajados, y cuya supresión no resultaría justificada, toda vez que responden a la idea de racionalizar y ordenar adecuadamente las funciones directivas horizontales en los Ministerios y Consejerías, lo cual requiere una organización básica y una coordinación. En el caso de que no existieran las Secretarías Generales Técnicas, sus funciones serían ejercidas de un modo disperso, incluso podrían dar lugar a la proliferación de órganos o servicios con funciones semejantes en un mismo Ministerio, como aconteció en los breves momentos en que fueron suprimidas.

Sin embargo, el PLRJSP podía haber aprovechado la ocasión para acrecentar sus funciones, siempre bajo la inmediata dependencia del Subsecretario, de cara a dar respuesta a los nuevos retos que presenta la Administración española en materias como legislación inteligente, innovación en la prestación de servicios, administración electrónica o transparencia, por citar sólo algunos. La Secretaría General Técnica tiene en su semilla la posibilidad de actuar como verdadero catalizador del proceso de reforma administrativa que ha impulsado el Gobierno.

\section{BIBLIOGRAFÍA}

CARRO MARTÍNEZ, Antonio: "Secretarías Generales Técnicas", en AA.VV.: Estudios de Derecho Administrativo. Libro Jubilar del Consejo de Estado. Editorial Instituto de Estudios Políticos, Madrid, 1972.

CORSO, Pompeo: La funzione consultiva. Editorial CEDAM, Padua, 1942.

DIETTA, Javier: Las Secretarías Generales Técnicas. Editorial Secretaría General Técnica de la Presidencia del Gobierno, Madrid, 1961.

FONT I LLOVET, Tomás: “Órganos consultivos”, Revista de Administración Pública, núm. 108, 1985.

GARCÍA DE ENTERRÍA Y MARTÍNEZ CARANDE, Eduardo: La Administración española: estudios de ciencia administrativa. Editorial Cívitas, Madrid, 1999.

-: “Aspectos de la Administración consultiva (Prólogo a la traducción española de Mooney)", en Revista de Administración Pública, núm. 24, 1957.

GASPARRI, Pietro: L'amministrazione consultiva. Editorial Nistri Lischi, Pisa, 1942.

SANTAMARIA PASTOR, Juan Alfonso: Fundamentos de Derecho Administrativo. Editorial CEURA, Madrid, 1988.

SANTOS GAONA, David: "La Secretaría General Técnica: evolución de un órgano característico en la Administración General del Estado”, en Diario La Ley, Sección Doctrina, 1997, Ref. D-191, tomo 4. 